\title{
Zebrafish shares common metabolic pathways with mammalian olanzapine- induced obesity
}

\author{
Pukar Khanal ${ }^{1 *}$ D, B. M. Patil ${ }^{*^{*}}$ and Banappa. S. Unger ${ }^{2}$
}

\begin{abstract}
Background: Olanzapine is one of the most prescribed antipsychotic agents in the pharmacotherapy of psychiatric illness; however, it is associated with multiple side effects primarily obesity. Multiple investigations have been made to model the olanzapine-induced obesity in rodent models which was found to be dose-dependent, gender-dependent, and speciesdependent. Danio rerio is a choice of an animal model to understand the pathogenesis of multiple diseases. The present study dealt to understand the olanzapine-associated obesity in zebrafish using in silico and wet-lab experimental protocols by performing gene set enrichment analysis, phylogeny comparison of receptors, and assessing the effect of olanzapine on metabolic rate, lipid metabolism, body weight, and food intake in zebrafish.
\end{abstract}

Results: The metabolic pathway was predicted to be majorly modulated by olanzapine in human, rat, mouse, and zebrafish. A clade of receptors of rat, mouse, and human receptor for feeding and satiety center was found similar to zebrafish. The decrease in lipid metabolism was observed in zebrafish larvae if exposed to olanzapine solution. Similarly, there was a significant decrease in metabolic rate in $200 \mu \mathrm{M}$ and $400 \mu \mathrm{M}$ concentration of olanzapine.

Conclusion: Enrichment analysis predicted the probable modulation of metabolic pathways in zebrafish if exposed to olanzapine. Further, olanzapine was identified to play a prime role in decreasing lipid metabolism and metabolic rate and increasing food intake and weight gain in zebrafish which suggests the validation of this model for olanzapine-induced obesity.

Keywords: Danio rerio, Lipid metabolism, Metabolic rate, Olanzapine-induced obesity, Zebrafish

\section{Background}

The current pharmacotherapy of psychiatric illness utilizes many atypical antipsychotic molecules in which olanzapine reserve its own importance in the major portion of prescription due to its high efficacy. However, the molecule is associated with multiple side effects, i.e. diabetes, dyslipidemia, and cardiovascular system (CVS) complications including obesity [1-3]. Many, attempts have been made to understand the mechanism for olanzapine-induced weight gain in various rodent models. However, the effects of olanzapine observed in rodent

\footnotetext{
*Correspondence: pukarkhanal58@gmail.com; bmpatil59@hotmail.com 'Department of Pharmacology and Toxicology, KLE College of Pharmacy, KLE Academy of Higher Education and Research (KAHER), Belagavi 590010, India
} Full list of author information is available at the end of the article models were gender-dependent, dose-dependent, and duration-dependent [4-8] reflecting the lack of an adequate model to represent the pathogenesis of olanzapineinduced obesity. Further, rodent models conserve the property of being unwieldy, expensive, and are allied with ethical issues for their utilization in research. This limitation kindled us to identify a new simple and alternative animal model for olanzapine-induced obesity.

Danio rerio, commonly identified as zebrafish, is an alternative animal model that has been extensively utilized in biomedical research [9] due to its similarity in physiological and metabolic pathways with Homo sapiens and other rodent animal models. Further, it has got popularity in lipid research, mainly for lipoprotein metabolism, lipid absorption and deposition, hepatic 
steatosis, obesity, diabetes, and other metabolic disorders [10]. Further, these vertebrates are also reported to share parallel pathophysiological pathways to mammals for diet-induced obesity [11]. These reports kindled us to investigate if olanzapine-induced abnormalities primarily lipid metabolism, metabolic rate, food intake, and weight gain can be expressed in zebrafish or not. To fulfill this hypothesis, we utilized the cheminformatics tools to predict the olanzapine-induced gene expression profile in Homo sapiens, Rattus norvegicus, Mus musculus, and Danio rerio, similarity index of the receptors available in the feeding, and satiety center. Further, the effect of olanzapine on lipid metabolism, metabolic rate, food intake, and weight gain was evaluated via experimental protocols.

\section{Methods}

Olanzapine-induced gene expression and gene set enrichment analysis

Canonical SMILES of olanzapine was retrieved from the PubChem database (https://pubchem.ncbi.nlm.nih.gov/) and queried for the probable mRNA-based gene expression using DIGEP-Pred [12]. All the expressed genes with probable activity $(\mathrm{Pa})$ greater than probable inactivity $(\mathrm{Pi})$ were queried in STRING [13] database to evaluate the protein-protein interaction for Homo sapiens, Rattus norvegicus, Mus musculus, and Danio rerio with reference to Kyoto Encyclopedia of Genes and Genomes (KEGG) pathway (https://www.genome.jp/kegg/pathway.html) database.

\section{Phylogenetic comparison of olanzapine-modulated receptors}

Proteins modulated by the olanzapine were identified from BindingDB [14] which works based on the principle "similar compounds tend to bind the same proteins" by querying canonical SMILES. The amino acid sequences of protein molecules for Homo sapiens, Rattus norvegicus, Mus musculus, and Danio rerio were retrieved from the NCBI database (https://www.ncbi. nlm.nih.gov/). The accession number of protein molecules subjected to phylogenic comparisons is summarized in Table 1. Amino acid sequences were aligned using multiple sequence alignment, and the phylogenic tree was constructed using the UPGMA clustering method. The bootstrap score was used to assess the similarity score between the protein molecules.

\section{Ethical approval and housing of zebrafish}

The experiment was performed after receiving ethical clearance from the IAEC, accession number KLECOP/ CPCSEAReg.No.221/PO/Re/S/2000/CPCSEA Res.25-09/ $09 / 2017$. Adult wild zebrafish of $2.5-3.5 \mathrm{~cm}$ were purchased from Fish-O-fish aquarium, Nehru Nagar Kurla (E) Mumbai and were housed under 14:10 light/dark photoperiod in a re-circulating aqueous system (water temperature $26 \pm 1{ }^{\circ} \mathrm{C}$, dissolved oxygen (measured using dissolved oxygen kit, HighMedia) > $4 \mathrm{mg} / \mathrm{L}$, conductivity 500-650 $\mu \mathrm{S} \mathrm{cm}^{-1}$ (maintained using Red Sea Salt), $\mathrm{pH}$ 6.8-7.4, and total dissolved salt (TDS) 250 to $325 \mathrm{ppm}$ ) and fed with dry flakes (once) and brine shrimps (twice) daily. Ten percent of total system water was replaced with new RO-purified water to maintain the water condition.

\section{Breeding and maintenance of fertilized embryos}

Adult zebrafish were allowed to mate in the ratio of 2:3. Initially, before the beginning of the dark photoperiod, the animals were separated and mixed together just before the beginning of light photoperiod, and fishes are allowed to mate. After 30 to $45 \mathrm{~min}$, the embryos were collected, washed, and maintained in embryo medium (HBSS Sigma). The fish were returned to their cages allowing a week of resting period before two successive breedings. Embryos were washed at 6 and $24 \mathrm{hpf}$ to remove the coagulated embryos; a percentage of coagulated embryos and hatched larvae were recorded at 24 and $72 \mathrm{~h}$, respectively.

\section{Selection of dose}

OECD 236 guidelines were followed to perform the fish embryonic toxicity (FET) which identified lethal concentration $\left(\mathrm{LC}_{50}: 64 \mu \mathrm{M}\right)$ and maximum non-lethal concentration (MNLC:50 $\mu \mathrm{M}$ ) of olanzapine in $72 \mathrm{hpf}$ larvae. Hence, five different concentrations of olanzapine in geometric series were chosen to evaluate the effect of olanzapine on lipid metabolism and metabolic rate. Further, metabolic rate was evaluated in a broader range of drug concentrations, i.e. below and above the MNLC since the change in metabolic rate was not observed in lower concentrations.

\section{Effect of olanzapine on lipid metabolism in zebrafish larvae}

The effect of olanzapine on lipid metabolism was assessed in $72 \mathrm{hpf}$ larvae [15]. Zebrafish larvae were exposed to multiple concentrations of olanzapine for 24 $\mathrm{h}$ at $28{ }^{\circ} \mathrm{C}$. After $24 \mathrm{~h}$, larvae were fixed in $4 \%$ paraformaldehyde, and Oil Red O (ORO) imaging procedure was performed under a dissecting stereoscopic microscope (Olympus Co., Tokyo, Japan). ORO was then quantified to determine the accumulation of lipids in different parts of larvae. The amount of lipid was quantified using the Fiji (Image J) software under red, green, and blue channels.

Effect of olanzapine in metabolic rate in zebrafish larvae Whole-body metabolic rate assay [16] was performed to evaluate the effect of olanzapine on metabolic rate with minor modifications. Briefly, $72 \mathrm{hpf}$ zebrafish larvae were 
Table 1 Accession number of proteins retrieved from NCBI

\begin{tabular}{lllll}
\hline Receptor & \multicolumn{3}{l}{ Accession number of receptor molecule of organisms } & \\
\cline { 2 - 5 } & Homo sapiens & Rattus norvegicus & Mus musculus & Danio rerio \\
\hline 5-HT 2A & AAB31320.1 & NP058950.1 & NP766400.1 & XP689300.7 \\
5-HT2C & AAB40898.1 & NP036897.2 & NP032338.3 & ABP04055.1 \\
a-2A & AAK51162.1 & NP036871.3 & NP03144304 & NP997520.3 \\
a-2C & NP_000674.2 & NP612515.1 & NP031444.2 & NP997522.1 \\
D4 & NP_000788.2 & AAA18588.1 & AAC52190.1 & NP001012638.2 \\
D2 & AAC78779.1 & NP036679.1 & NP034207.2 & NP898891.1 \\
D3 & AAB08750.1 & NAA41076.1 & NP031903.1 & AAN87173.1 \\
SERT & P31645.1 & NP034614.2 & NP001170930.1 \\
NTS1 & AAR07901.1 & NP037166.2 & XP021329279.1 \\
H1 & NP_001091683.1 & NP001102437.1 & NP001304053.1 & NP001036196.1 \\
M1 & NP_000729.2 & NP058714.1 & NP001106167.1 & XP001334664.4 \\
M2 & NP_001006633.1 & NP542951.1 & NP987076.2 & NP840086.1 \\
5-HT 1A & NP_000515.2 & NP112278.1 & NP032334.2 & NP001116793.1 \\
5-HT 7 & AAH47526.1 & NP036717.1 & CAQ76702.1 & XP003199632.2 \\
a-1A & AAA35496.1 & NP075227.1 & AAC02658.1 & XP001922013.3 \\
5-HT 6 & AAA92622.1 & AAA63477.1 & NP067333.1 & XP009295353.1 \\
D1 & AAB26273.1 & NP077341.2 & NP001278730.1 & AC142369.1
\end{tabular}

exposed to five different concentrations $(200 \mu \mathrm{M}$, $100 \mu \mathrm{M}, 50 \mu \mathrm{M}, 25 \mu \mathrm{M}$, and $12.5 \mu \mathrm{M})$ of olanzapine and assay buffer $(0.01 \% \mathrm{w} / \mathrm{v}$ of phenol red in sodium bicarbonate solution at $\mathrm{pH} 8.0$ and conductivity $350 \mu \mathrm{M})$ in 96-well microtiter plate, and absorbance was recorded for $180 \mathrm{~min}$ at $570 \mathrm{~nm}$ at $10 \mathrm{~min}$ interval. The amount of acid produced over a period of time was quantified by using a linear regression curve.

Effect of olanzapine in food intake and weight gain Bodyweight was recorded at the interval of 3 days, and food intake (daily) for 21 days using thirty adult female zebrafish weighting $229 \pm 20 \mathrm{mg}$. The study design included five groups, each containing six zebrafish in each: Group 1, exposed to system water; Group 2, to $0.001 \%$ DMSO in system water; Group 3, exposed to $16.66 \mu \mathrm{M}$ olanzapine; Group 4, exposed to $5 \mu \mathrm{M}$ olanzapine; and Group 5, exposed to $0.5 \mu \mathrm{M}$ olanzapine. After the completion of the study, all adult zebrafish were allowed to rehabilitate separately with the adequate conditions and not utilized for any other experiments.

\section{Statistical analysis}

Results were expressed as mean \pm SEM. The significant difference among data was determined using one-way ANOVA followed by the Tukey test using the GraphPad Prism software version 5.0. The difference between mean was considered significant if $p$ value $<0.05$. The network of gene-pathway interaction was interpreated by edge count. The similarity index between proteins was compared via the bootstrap score using MEGA7.

\section{Results \\ Olanzapine-induced gene expression and gene set enrichment analysis}

Based on mRNA-based prediction, forty-five genes were predicted to be expressed; among them, twenty were downregulated and twenty-five were upregulated. Gene set enrichment predicted forty-five proteins to be modulated in Homo sapiens, forty-three in Rattus norvegicus and Mus musculus, and thirty-nine in Danio rerio. Similarly, SERPINA3 and C10ORF118 were not detected in Rattus norvegicus and Mus musculus and EVI2B, FNDC4, SERPINA3, CYP2E1, LST1, and NR1H2 in Danio rerio. Further, KEGG pathway analysis identified eight pathways to be modulated in Homo sapiens, nine in Rattus norvegicus, eight in Mus musculus, and three in Danio rerio. Among all, the metabolic pathway was common and was majorly modulated in all species. Figure 1 summarizes the detail pathway-gene interaction, and Table 2 summarizes the gene set enrichment of individual pathways of each species.

\section{Phylogenetic comparison of olanzapine-modulated receptors}

Among Rattus norvegicus, Mus musculus, and Danio rerio, receptors of Rattus norvegicus and Mus musculus 


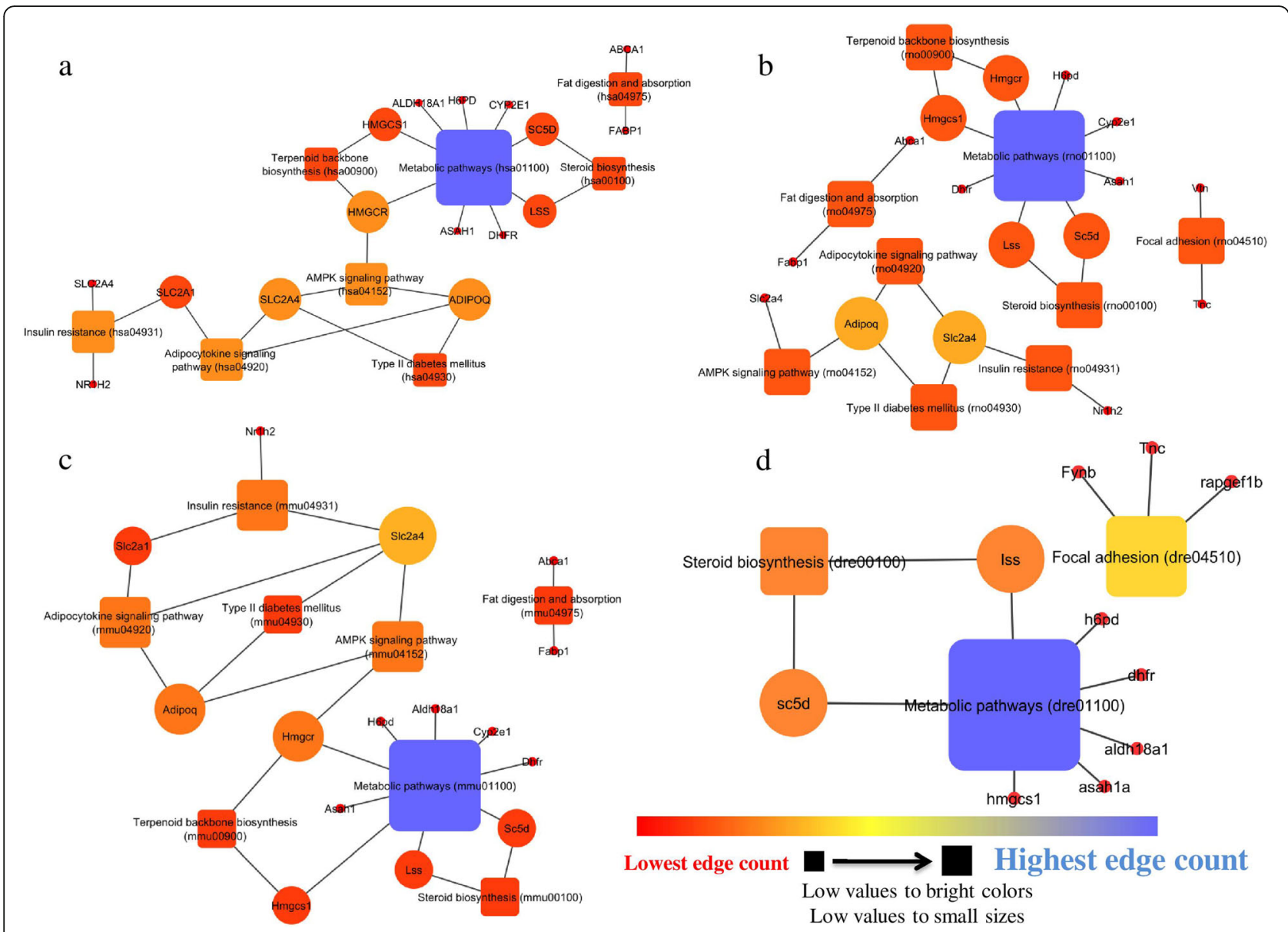

Fig. 1 Olanzapine-induced gene-pathway interaction a Homo sapiens, b Rattus norvegicus, c Mus musculus, and d Danio rerio

were more similar to Homo sapiens compared to Danio rerio. However, M2, 5HT-1A, and alpha $1 \mathrm{~A}$ receptors of Rattus norvegicus were more similar to Homo sapiens compared to Mus musculus. The phylogenic representation including a bootstrap score of the Danio rerio branch with a clade of Homo sapiens, Rattus norvergicus, and Mus musculus is presented in Fig. 2.

\section{Effect of olanzapine on lipid metabolism}

In $50 \mu \mathrm{M}$ olanzapine, the natural death of larvae occurred at $192 \mathrm{~h}$ of exposure (Fig. 3). Fish embryonic toxicity (FET) also reflected $50 \mu \mathrm{M}$ olanzapine as a maximum non-lethal concentration. Hence, multiple concentrations of olanzapine, i.e. $50 \mu \mathrm{M}, 25 \mu \mathrm{M}, 12.5 \mu \mathrm{M}$, $6.25 \mu \mathrm{M}$, and $3.125 \mu \mathrm{M}$, were chosen to expose $72 \mathrm{hpf}$ larvae. Accumulation of lipid increased significantly from lowest concentration $(3.125 \mu \mathrm{M}, p<0.05)$ to the highest concentration $(50 \mu \mathrm{M}, p<0.001)$ (Fig. 4) which was quantified by integrated optical density (IOD) of stain; represents the total amount of lipid present in the whole body of larvae.
Effect of olanzapine on metabolic rate in zebrafish larvae Empirical titration was performed by adding a known amount of acid $\left(\mathrm{H}^{+}\right)$in each well of 96-well microtiter plates and titrated with $50 \mu \mathrm{l}$ assay buffer $(0.01 \%$ $\mathrm{w} / \mathrm{v}$ phenol red). The linear equation $y=-0.3342 \mathrm{x}+$ 2.3768 was obtained with $R^{2}$ value of 0.997. Larvae exposed to the range of concentrations of olanzapine modulating lipid metabolism, body weight, and food intake had no significant effect to change the metabolic rate. However, exposure of larvae at higher concentration, i.e., $200 \mu \mathrm{M}$ and $400 \mu \mathrm{M}$ of olanzapine, showed a significant change in acid production at different time intervals (Fig. 5). Toxicity of phenol red was evaluated by exposing $72 \mathrm{hpf}$ zebrafish larvae to buffer at $\mathrm{pH} 8.0$ containing phenol red $(0.01 \% \mathrm{w} / \mathrm{v})$. Death of larvae in assay buffer began after the $4^{\text {th }}$ day of exposure. However, log-rank (Mantel-Cox) test showed in significant difference in death in assay buffer compared to system water suggesting that phenol red did not cause any toxic effect during the experiment (Fig. 6). 
Table 2 Olanzapine-induced gene set enrichment analysis in Homo sapiens, Rattus norvegicus, Mus musculus, and Danio rerio

\begin{tabular}{|c|c|c|c|c|c|}
\hline Organism & Pathway & Description & $\begin{array}{l}\text { Gene } \\
\text { count }\end{array}$ & Genes & $\begin{array}{l}\text { False discovery } \\
\text { rate }\end{array}$ \\
\hline \multirow[t]{8}{*}{$\begin{array}{l}\text { Homo } \\
\text { sapiens }\end{array}$} & hsa04975 & $\begin{array}{l}\text { Fat digestion and } \\
\text { absorption }\end{array}$ & 2 & FABP1, BCA1 & 0.0428 \\
\hline & hsa04931 & Insulin resistance & 3 & SLC2A1,SLC2A4, NR1H2 & 0.0428 \\
\hline & hsa04920 & $\begin{array}{l}\text { Adipocytokine signaling } \\
\text { pathway }\end{array}$ & 3 & SLC2A1,SLC2A4, ADIPOQ & 0.0428 \\
\hline & hsa04152 & AMPK signaling pathway & 3 & SLC2A4, ADIPOQ, HMGCR & 0.0428 \\
\hline & hsa01100 & Metabolic pathways & 9 & $\begin{array}{l}\text { ALDH18A1, DHFR, H6PD, LSS, SC5D, HMGCS1, CYP2E1, } \\
\text { HMGCR, ASAH1 }\end{array}$ & 0.0428 \\
\hline & hsa00900 & $\begin{array}{l}\text { Terpenoid backbone } \\
\text { biosynthesis }\end{array}$ & 2 & HMGCS1, HMGCR & 0.0428 \\
\hline & hsa00100 & Steroid biosynthesis & 2 & LSS, SC5D & 0.0428 \\
\hline & hsa04930 & Type II diabetes mellitus & 2 & SLC2A4, ADIPOQ & 0.0482 \\
\hline \multirow[t]{9}{*}{$\begin{array}{l}\text { Rattus } \\
\text { norvegicus }\end{array}$} & rno04920 & $\begin{array}{l}\text { Adipocytokine signaling } \\
\text { pathway }\end{array}$ & 3 & Adipoq, Slc2a4 & 0.0222 \\
\hline & rno04931 & Insulin resistance & 3 & Slc2a4, Nr1h2 & 0.0242 \\
\hline & rno04152 & AMPK signaling pathway & 3 & Adipoq, Slc2a4 & 0.0242 \\
\hline & rno01100 & Metabolic pathways & 8 & Cyp2e1, Hmgcr, Sc5d, Hmgcs1, Lss, H6pd, Dhfr, Asah1 & 0.0242 \\
\hline & rno00900 & $\begin{array}{l}\text { Terpenoid backbone } \\
\text { biosynthesis }\end{array}$ & 2 & Hmgcr, Hmgcs 1 & 0.0242 \\
\hline & rno00100 & Steroid biosynthesis & 2 & Sc5d, Lss & 0.0242 \\
\hline & rno04975 & $\begin{array}{l}\text { Fat digestion and } \\
\text { absorption }\end{array}$ & 2 & Fabp1, Abca1 & 0.0251 \\
\hline & rno04930 & Type II diabetes mellitus & 2 & Adipoq, SIc2a4 & 0.0315 \\
\hline & rno04510 & Focal adhesion & 3 & Vtn, Tnc & 0.0428 \\
\hline \multirow[t]{8}{*}{ Mus musculus } & mmu04975 & $\begin{array}{l}\text { Fat digestion and } \\
\text { absorption }\end{array}$ & 2 & Abca1, Fabp1 & 0.0283 \\
\hline & mmu04931 & Insulin resistance & 3 & Nr1h2, Slc2a4, Ic2a1 & 0.0283 \\
\hline & mmu04920 & $\begin{array}{l}\text { Adipocytokine signaling } \\
\text { pathway }\end{array}$ & 3 & Adipoq, Slc2a4, Slc2a1 & 0.0283 \\
\hline & mmu04152 & AMPK signaling pathway & 3 & Adipoq, Slc2a4, Hmgcr & 0.0283 \\
\hline & mmu01100 & Metabolic pathways & 9 & $\begin{array}{l}\text { Asah1, Cyp2e1, H6pd, Hmgcr, Dhfr, Aldh18a1, Hmgcs1, } \\
\text { Lss, Sc5d }\end{array}$ & 0.0283 \\
\hline & mmu00900 & $\begin{array}{l}\text { Terpenoid backbone } \\
\text { biosynthesis }\end{array}$ & 2 & Hmgcs1, Hmgcr & 0.0283 \\
\hline & mmu00100 & Steroid biosynthesis & 2 & Sc5d, Lss & 0.0283 \\
\hline & mmu04930 & Type II diabetes mellitus & 2 & Adipoq, SIc2a4 & 0.0374 \\
\hline \multirow[t]{3}{*}{ Danio rerio } & dre00100 & Steroid biosynthesis & 2 & sc5d, Iss & 0.0114 \\
\hline & dre01100 & Metabolic pathways & 7 & sc5d, hmgcs1, Iss, h6pd, dhfr, aldh18a1, asah1a & 0.0320 \\
\hline & dre04510 & Focal adhesion & 3 & fynb, tnc, rapgef $1 b$ & 0.0453 \\
\hline
\end{tabular}

Effect of olanzapine on food intake and weight gain Hyperphagia was observed from the $7^{\text {th }}$ day and continued till the $20^{\text {th }}$ day in adult zebrafish exposed to $0.5 \mu \mathrm{M}$ olanzapine. Similarly, zebrafish exposed to $0.5 \mu \mathrm{M}$ showed a significant increase in weight gain on the $12^{\text {th }}$ day and continued until the $20^{\text {th }}$ day (Fig. 7).

\section{Discussion}

The present study dealt to investigate whether olanzapine-induced metabolic changes can be demonstrated in zebrafish or not which can be further employed as an alternative experimental model. Before the performance of wet-lab experiments, we predicted the olanzapine-induced gene expression in four 


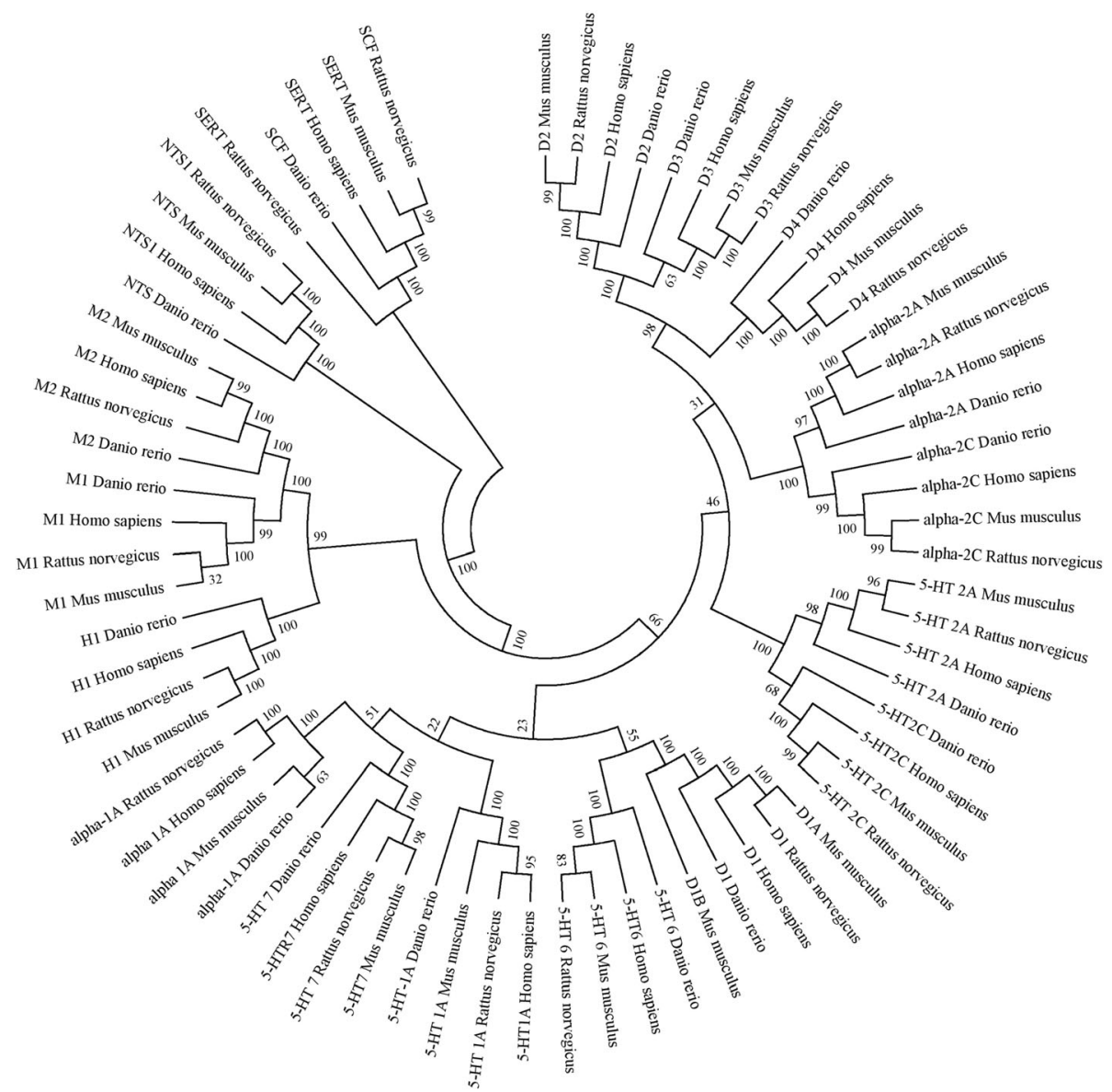

Fig. 2 Phylogeny comparison of receptors present in feeding and satiety center. The number at branching point refers to bootstrap score based on 500 replicates

different species. Interestingly, we identified a metabolic pathway to be common in all, modulating the highest number of gene sets. Further, a clade of proteins involved in feeding and satiety center of Danio rerio, Rattus norvegicus, and Mus musculus was found to be similar with Homo sapiens. This reflected that the receptors present in hunger and satiety center are closely related among four different species; suggested the feeding behavior of Danio rerio could be similar to Homo sapiens, Rattus norvegicus, and Mus musculus. These two observations further kindled us to evaluate the effect of olanzapine in lipid metabolism, metabolic rate, food intake, and weight gain in zebrafish larvae.

Literature reflects that olanzapine-induced obesity is associated with hyperphagia [17] leading to weight gain. This hypothesis of olanzapine-induced obesity has been successively demonstrated in rodent models [4-8]. In the present study, exposure of adult zebrafish in olanzapine showed an increase in food intake and weight gain in $0.5 \mu \mathrm{M}$ concentration. Hence, the study was further designed to understand the effect of olanzapine on lipid metabolism in zebrafish larvae.

Further, a correlation has been made between olanzapine-induced obesity and anomalous metabolism of the lipids $[18,19]$. An elevated level of free fatty acids, TGs, total cholesterol, LDL, and low level of HDL have been reported in olanzapine-induced obesity directing towards dyslipidemia and its associated complications $[20,21]$. Clinical case for dyslipidemia condition has been reported in the patients under the pharmacotherapy of olanzapine which is additionally demonstrated in the rodent models by numerous investigators [4-8]. Similarly, in the current study, exposure of $72 \mathrm{hpf}$ larvae in the solution of olanzapine for $24 \mathrm{~h}$ showed a decrease in lipid metabolism which was confirmed via the Oil Red O staining technique. This altered lipid metabolism in olanzapine-exposed larvae reflects "dwindle lipid metabolism" as one of the important reasons for olanzapine-induced obesity. 


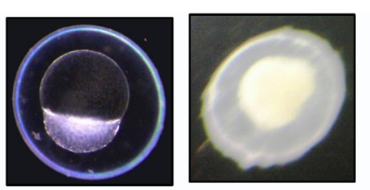

Fertilized embryo coagulated embryo

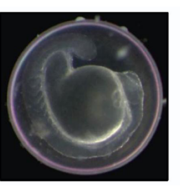

Formation of somites

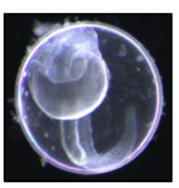

Tail detachmen

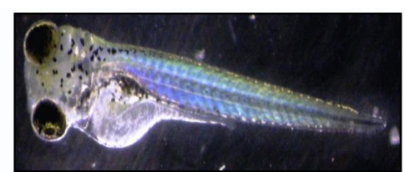

Hatched larvae

\section{Kaplan-Meier Curve for Maximum Non Lethal Concentration}

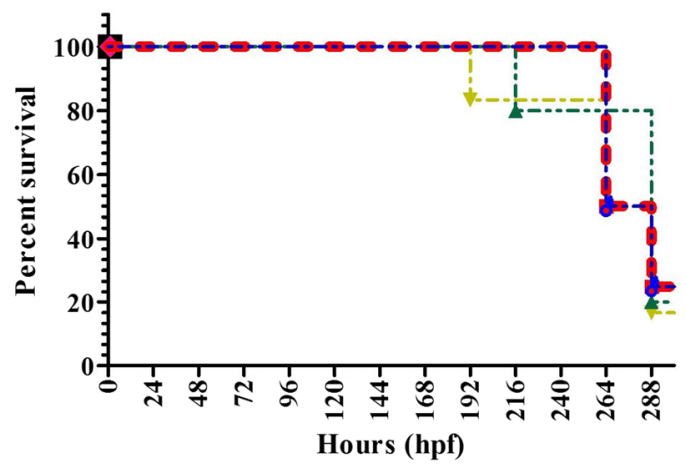

- ช́- $6.25 \mu \mathrm{M}$ Olanzapine

ㅁ. $12.5 \mu \mathrm{M}$ Olanzapine

- $25 \mu \mathrm{M}$ Olanzapine

$\Rightarrow \quad 50 \mu \mathrm{M}$ Olanzapine

$\sim \mathrm{nC}$

- $\mathrm{sC}$

Fig. 3 Survival curve (Kaplan-Meier curve) of larvae exposed to olanzapine. nC, negative control, sC, solvent control. Total number of larvae exposed to each concentration $(n)=6$

The decrease in lipid metabolism is linked with repression in energy expenditure [22] which occurs due to variation in basal metabolic rate [23-25]. This variation of basal metabolic rate is closely related to abnormal metabolism of lipids [26]. Total respiratory compliance is decreased in the obese population compared to the normal population. This reduction in total respiratory compliance is due to increased pulmonary blood volume, decrease in chest wall, and accumulation of fat in and around the ribs, diaphragm, and abdomen. Interestingly, this observation was also recorded in the present study during the assessment of lipid metabolism in zebrafish larvae. Reduction in total respiratory compliance causes an increase in respiratory resistance [26-28] and high anaerobic respiration [26, 29] leading to lactic acidosis reflecting the decreased metabolic rate. Metabolic rate was assessed in zebrafish larvae by utilizing an anaerobic system which is based on the principle of accumulation of lactic and carbonic acid [16]. Larvae exposed to olanzapine showed increased acid production $\left(\mathrm{H}^{+}\right)$leading to a decrease in basal metabolic rate.

Further, it has been predicted that a single compound can bind/modulate multiple proteins and regulate pathways associated with them $[30,31]$. So, there is a possibility that olanzapine can also bind or regulate multiple proteins/pathways related to the homeostasis of appetite and energy expenditure. Hence, further investigation needs to assess the role of olanzapine-modulated proteins/pathways in the development and progression of obesity and other side effects.

\section{Conclusion}

The gene-set enrichment analysis identified five common genes which are also expressed in human and rodents. However, the role of each gene, i.e. h6pd, dhfr, aldh18a1, asah1a, and hmgcs1, needs to be extensively investigated for olanzapine-induced metabolic abnormalities in zebrafish and other rodent models. However, this predication helped us to identify olanzapine-induced metabolic abnormalities, i.e., decreased lipid metabolism and metabolic rate and increased food intake and body weight. Limiting to the present study, change in the metabolic rate occurred in the toxic concentration of olanzapine, i.e. $400 \mu \mathrm{M}$ and $200 \mu \mathrm{M}$ making suspicious for change in metabolic rate due to energy expenditure. Further, approaches should be framed to evaluate biochemical parameters and assess gene expression profiles related to olanzapine-induced obesity in zebrafish using well-designed wet-lab protocols to confirm the current findings.

\section{Supplementary information}

Supplementary information accompanies this paper at https://doi.org/10. 1186/s43094-020-00049-7.

Additional file 1. ARRIVER1 


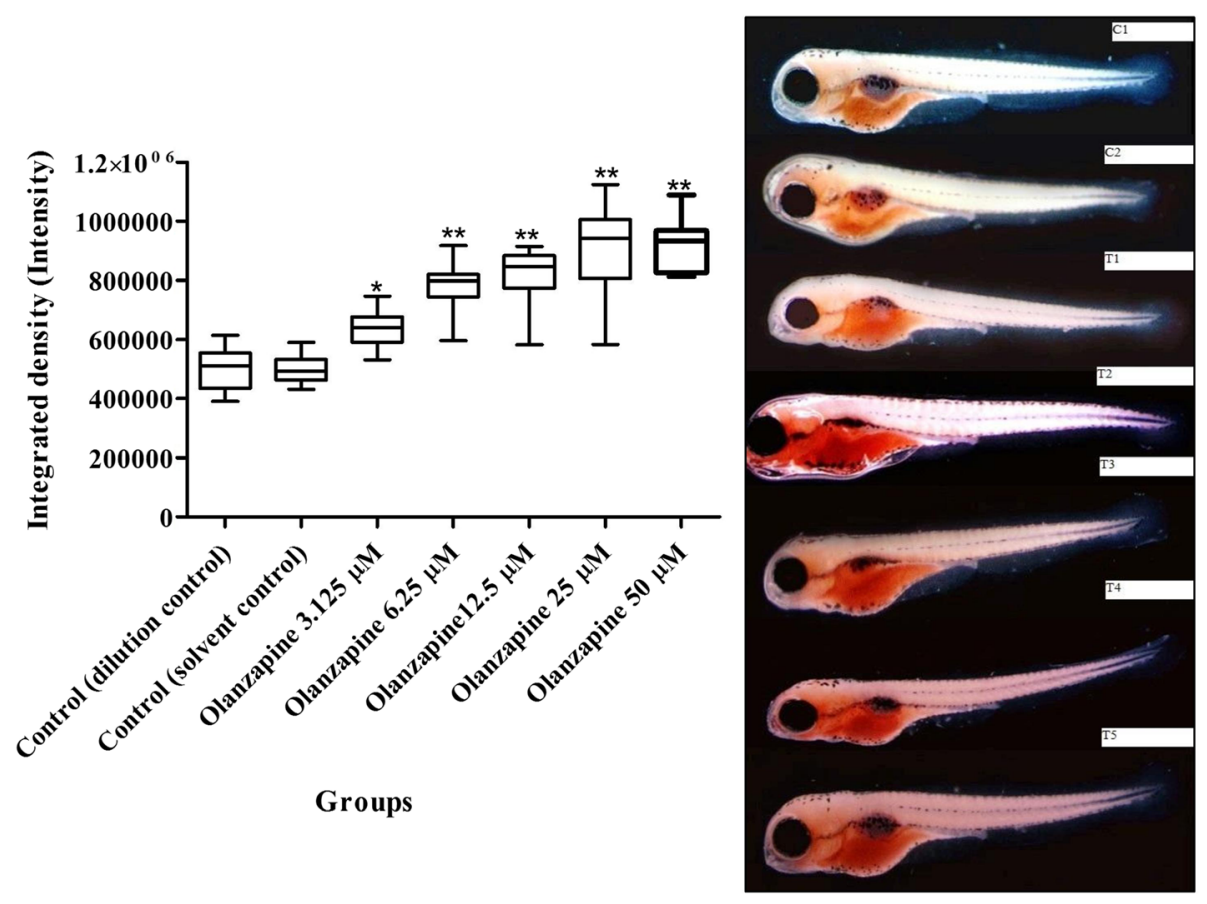

Fig. 4 Effect of olanzapine $(50 \mu \mathrm{M}, 25 \mu \mathrm{M}, 12.5 \mu \mathrm{M}, 6.25$, and $3.125 \mu \mathrm{M})$ in lipid metabolism in zebrafish larvae. Zebrafish at 72 hpf were exposed to $\mathrm{C} 1$, system water; $\mathrm{C} 2,0.0001 \% \mathrm{v} / \mathrm{v}$ DMSO; T1, $3.125 \mu \mathrm{M} ; \mathrm{T} 2,6.25 \mu \mathrm{M} ; \mathrm{T} 3,12.5 \mu \mathrm{M} ; \mathrm{T} 4,25 \mu \mathrm{M}$, and T5, $50 \mu \mathrm{M}$ of olanzapine. Lipids of zebrafish gut and vasculature increased with increase in the concentration of olanzapine. Scale $100 \mu \mathrm{m}$. Number of larvae in each groups $(n)=10$. All the data are expressed in mean $\pm \mathrm{SEM} .{ }^{*} p<0.05,{ }^{*} p<0.01$ compared to solvent control
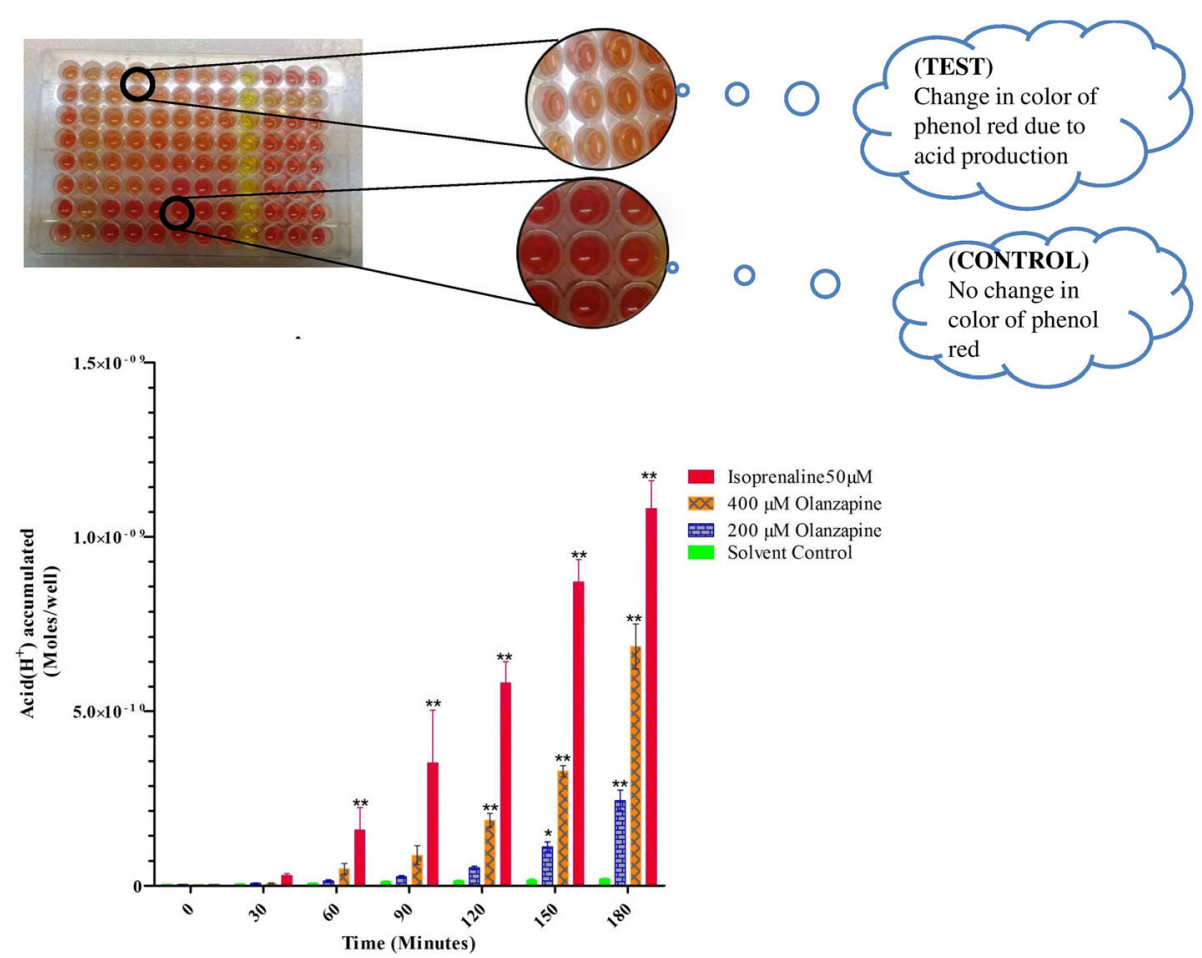

Fig. 5 Effect of olanzapine $(400 \mu \mathrm{M}$ and $200 \mu \mathrm{M})$ on metabolic rate. Data are shown in 30 min interval. All the data are expressed in mean \pm SEM. Number of larvae in each group $(n)=8 .{ }^{*} p<0.05,{ }^{* *} p<0.001$ significantly different versus solvent group 


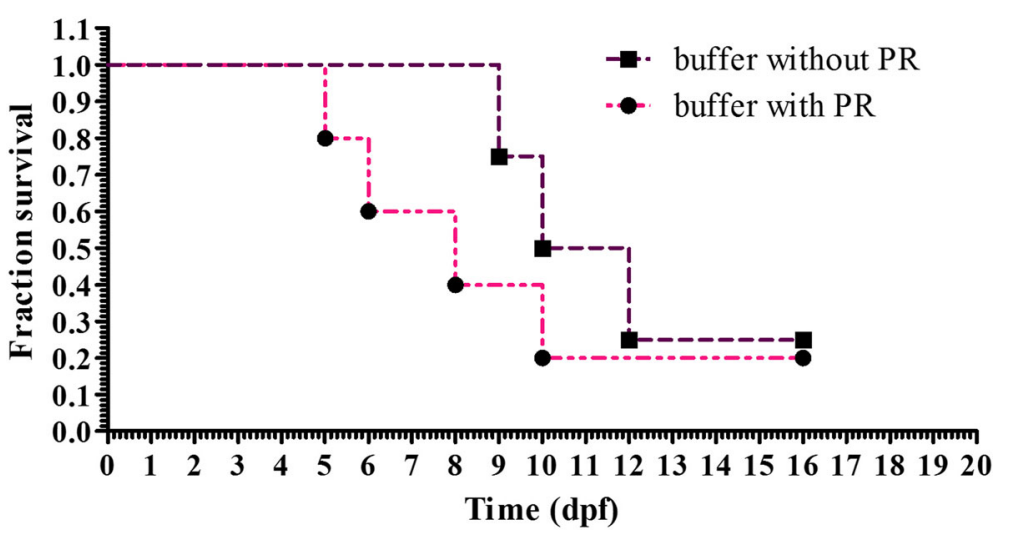

Fig. 6 Survival curve of larvae exposed to buffer in the presence and absence of phenol red. PR, phenol red

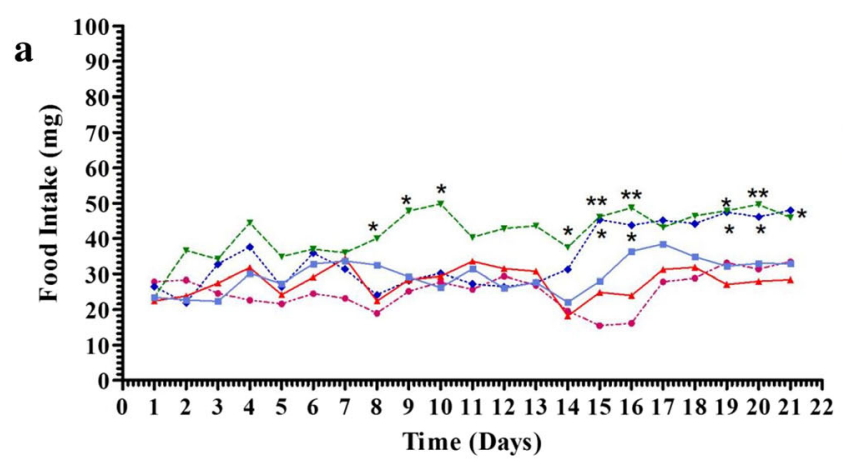

-.- olanzapine $16.66 \mu \mathrm{M}$

..... olanzapine $5 \mu \mathrm{M}$

-*-. olanzapine $0.5 \mu \mathrm{M}$

- control (solvent control)

- control (dilution control)

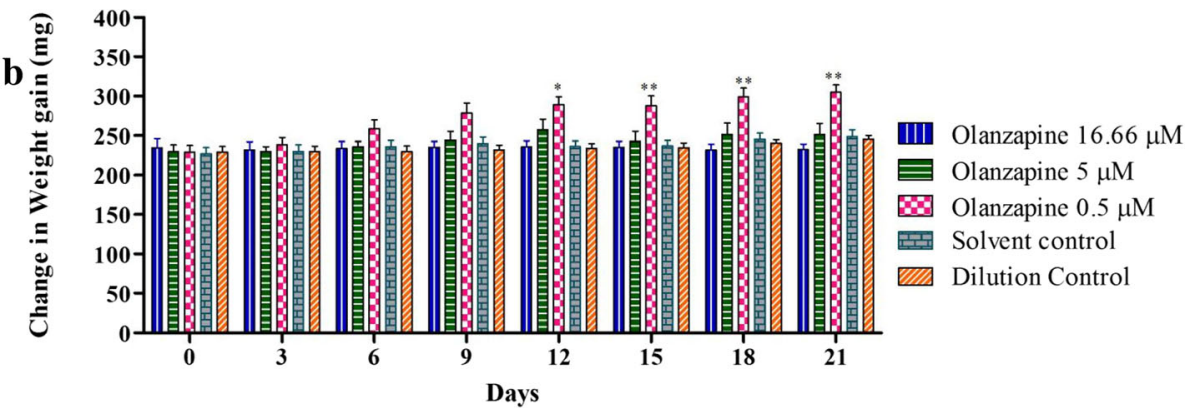

Fig. 7 Effect of olanzapine on $\mathbf{a}$ food intake and $\mathbf{b}$ body weight. All the data are expressed in mean \pm SEM. Number of adult zebrafish in each group $(n)=6 .{ }^{*} p<0.05,{ }^{* *} p<0.001$ significantly different versus solvent group 


\section{Abbreviations}

ANOVA: Analysis of variance; CVS: Cardiovascular system; FET: Fish embryonic toxicity; HDL: High-density lipoprotein; IAEC: Institutional Animal Ethics Committee; KEGG: Kyoto Encyclopedia of Genes and Genomes; MNLC: Maximum non-lethal concentration; NCBI: National Center for Biotechnology Information; OECD: Organisation for Economic Co-operation and Development; ORO: Oil Red O; Pa: Probable activity; Pi: Probable inactivity; SMILES: Simplified molecular-input line-entry system; TDS: Total dissolved salt; UPGMA: Unweighted pair group method with arithmetic mean

\section{Acknowledgements}

The authors are thankful to Apotex Research Private Limited for providing the gift sample of olanzapine, KLE College of Pharmacy for financing the study as intramural research, and ICMR-NITM Belagavi for providing the necessary facilities throughout the study.

\section{Authors' contributions}

PK contributed in experimental design for in silico study, performed the wetlab experiment, and drafted the manuscript. BMP introduced a concept for utilizing zebrafish in olanzapine-induced obesity in zebrafish and reviewed the manuscript. BSU provided the necessary facilities for the experimental work, trained PK in develpoing the skills in zebrafish experiments and contributed in drafting the manuscript. All authors read and approved the final manuscript.

\section{Funding}

This work has not received any funding from any National and International agencies.

\section{Availability of data and materials}

The data for this work are available with Pukar Khanal upon request.

\section{Ethics approval and consent to participate}

The experiment was performed after receiving ethical clearance from Institutional Animal Ethical Committee (IAEC) at KLE College of Pharmacy, Belagavi, KAHER, Belagavi accession number KLECOP/CPCSEA-Reg. No.221/ PO/Re/S/2000/CPCSEA Res.25-09/09/2017.

\section{Consent for publication}

Not applicable.

\section{Competing interests}

The authors declared no conflict of interest.

\section{Author details}

${ }^{1}$ Department of Pharmacology and Toxicology, KLE College of Pharmacy, KLE Academy of Higher Education and Research (KAHER), Belagavi 590010, India. ${ }^{2}$ Division of Pharmacology and Toxicology, Indian Council of Medical Research-National Institute of Traditional Medicine (ICMR-NITM), Belagavi 590010, India.

Received: 11 November 2019 Accepted: 30 June 2020 Published online: 23 July 2020

\section{References}

1. Lord CC, Wyler SC, Wan R, Castorena CM, Ahmed N, Mathew D, Lee S, Liu C, Elmquist JK (2017) The atypical antipsychotic olanzapine causes weight gain by targeting serotonin receptor 2C. J Clin Invest 127(9):3402-3406. https:// doi.org/10.1172/JC193362

2. Redinger RN (2007) The pathophysiology of obesity and its clinical manifestations. Gastroenterol Hepatol 3(11):856. https://www.ncbi.nlm.nih. gov/pmc/articles/PMC3104148/pdf/GH-03-856.pdf

3. Cooper GD, Pickavance LC, Wilding JP, Halford JC, Goudie AJ (2005) A parametric analysis of olanzapine-induced weight gain in female rats. Psychopharmacology (Berl) 181(1):80-89 https://doi.org/10.1007/s00213005-2224-4

4. Shah R, Subhan F, Ali G, Ullah I, Ullah S, Shahid M, Ahmad N, Fawad K (2016) Olanzapine induced biochemical and histopathological changes after its chronic administration in rats. Saudi Pharm J 24(6):698-704. https://doi. org/10.1016/j.jsps.2015.06.006
5. Pouzet B, Mow T, Kreilgaard M, Velschow S (2003) Chronic treatment with antipsychotics in rats as a model for antipsychotic-induced weight gain in human. Pharmacol Biochem Behav 75(1):133-140. https://doi.org/10.1016/ s0091-3057(03)00042-x

6. Choi S, DiSilvio B, Unangst J, Fernstrom JD (2007) Effect of chronic infusion of olanzapine and clozapine on food intake and body weight gain in male and female rats. Life Sci 81(12):1024-1030. https:/doi.org/10.1016/j.lfs.2007.08.009

7. Davey KJ, O'Mahony SM, Schellekens H, O'Sullivan O, Bienenstock J, Cotter PD, Dinan TG, Cryan JF (2012) Gender-dependent consequences of chronic olanzapine in the rat: effects on body weight, inflammatory, metabolic and microbiota parameters. Psychopharmacology (Berl) 221(1):155-169. https:// doi.org/10.1007/s00213-011-2555-2

8. Albaugh VL, Henry CR, Bello NT, Hajnal A, Lynch SL, Halle B, Lynch CJ (2006) Hormonal and metabolic effects of olanzapine and clozapine related to body weight in rodents. Obesity (Silver Spring) 14(1):36-51. https://doi.org/ 10.1038/oby.2006.6

9. Brittijn SA, Duivesteijn SJ, Belmamoune M, Bertens LF, Bitter W, Debruijn JD, Champagne DL, Cuppen E, Flik G, Vandenbroucke-Grauls CM, Janssen RA (2009) Zebrafish development and regeneration: new tools for biomedical research. Int J Dev Biol 53(5-6):835-850. https://doi.org/10.1387/ijdb. 082615sb

10. Hölttä-Vuori M, Salo VT, Nyberg L, Brackmann C, Enejder A, Panula P, Ikonen E (2010) Zebrafish: gaining popularity in lipid research. Biochem J 429(2): 235-242. https://doi.org/10.1042/BJ20100293

11. Oka T, Nishimura $Y$, Zang $L$, Hirano M, Shimada $Y$, Wang Z, Umemoto N, Kuroyanagi J, Nishimura N, Tanaka T (2010) Diet-induced obesity in zebrafish shares common pathophysiological pathways with mammalian obesity. BMC Physiol 10(1):21 https://doi.org/10.1186/1472-6793-10-21

12. Lagunin A, Ivanov S, Rudik A, Filimonov D, Poroikov V (2013) DIGEP-Pred: web service for in silico prediction of drug-induced gene expression profiles based on structural formula. Bioinformatics 29(16):2062-2063. https://doi. org/10.1093/bioinformatics/btt322

13. Szklarczyk D, Morris JH, Cook H, Kuhn M, Wyder S, Simonovic M, Santos A, Doncheva NT, Roth A, Bork P, Jensen L, von Mering C (2017) The STRING database in 2017: quality-controlled protein-protein association networks, made broadly accessible. Nucleic Acids Res 45(Database issue):D362-D368. https://doi.org/10.1093/nar/gkw937

14. Liu T, Lin Y, Wen X, Jorissen RN, Gilson MK (2007) BindingDB: a webaccessible database of experimentally determined protein-ligand binding affinities. Nucleic Acids Res 35(Database issue)::198-201. https://doi.org/10. 1093/nar/gkl999

15. Ho JC, Hsiao CD, Kawakami K, William KF (2016) Triclosan (TCS) exposure impairs lipid metabolism in zebrafish embryos. Aquat Toxicol 173:29-35. https://doi.org/10.1016/j.aquatox.2016.01.001

16. Makky K, Duvnjak P, Pramanik K, Ramchandran R, Mayer AN (2008) A wholeanimal microplate assay for metabolic rate using zebrafish. J Biomol Screen 13(10):960-967. https://doi.org/10.1177/1087057108326080

17. Mathews J, Newcomer JW, Mathews JR, Fales CL, Pierce KJ, Akers BK, Marcu I, Barch DM (2012) Neural correlates of weight gain with olanzapine. Arch Gen Psychiatry 69(12):1226-12237. https://doi.org/10.1001/ archgenpsychiatry.2012.934

18. Parekh S, Anania FA (2007) Abnormal lipid and glucose metabolism in obesity: implications for nonalcoholic fatty liver disease. Gastroenterology 132(6):2191-2207. https://doi.org/10.1053/j.gastro.2007.03.055

19. Consitt LA, Bell JA, Houmard JA (2009) Intramuscular lipid metabolism, insulin action, and obesity. IUBMB life 61(1):47-55. https://doi.org/10.1002/ iub.142

20. Ni Y, Zhao L, Yu H, Ma X, Bao Y, Rajani C, Loo LW, Shvetsov YB, Yu H, Chen T, Zhang $Y$ (2015) Circulating unsaturated fatty acids delineate the metabolic status of obese individuals. EBioMedicine 2(10):1513-1522. https://doi.org/10.1016/j.ebiom.2015.09.004

21. Ebbert JO, Jensen MD (2013) Fat depots, free fatty acids, and dyslipidemia. Nutrients 5(2):498-508. https://doi.org/10.3390/nu5020498

22. Choi MS, Kim YJ, Kwon EY, Ryoo JY, Kim SR, Jung UJ (2015) High-fat diet decreases energy expenditure and expression of genes controlling lipid metabolism, mitochondrial function and skeletal system development in the adipose tissue, along with increased expression of extracellular matrix remodelling-and inflammation-related genes. Br J Nutr 113(6):867-877. https://doi.org/10.1017/S0007114515000100

23. Wone BW, Donovan ER, Cushman JC, Hayes JP (2013) Metabolic rates associated with membrane fatty acids in mice selected for increased 
maximal metabolic rate. Comp Biochem Physiol A Mol Integr Physiol 165(1): 70-78. https://doi.org/10.1016/..cbpa.2013.02.010

24. Heindel JJ, Blumberg B, Cave M, Machtinger R, Mantovani A, Mendez MA, Nadal A, Palanza P, Panzica G, Sargis R, Vandenberg LN (2017) Metabolism disrupting chemicals and metabolic disorders. Reprod Toxicol 68:3-33. https://doi.org/10.1016/j.reprotox.2016.10.001

25. Weber JM (2011) Metabolic fuels: regulating fluxes to select mix. J Exp Biol 214(Pt 2):286-294. https://doi.org/10.1242/jeb.047050

26. Parameswaran K, Todd DC, Soth M (2006) Altered respiratory physiology in obesity. Can Respir J 13(4):203-210. https://doi.org/10.1155/2006/834786

27. Melo LC, Silva MA, Calles AC (2014) Obesity and lung function: a systematic review. Einstein (Sao Paulo) 12(1):120-125 https://doi.org/10.1590/S167945082014RW2691

28. Porhomayon J, Papadakos P, Singh A, Nader ND (2011) Alteration in respiratory physiology in obesity for anesthesia-critical care physician. HSR Proc Intensive Care Cardiovasc Anesth 3(2):109-118 https://www.ncbi.nlm. nih.gov/pmc/articles/PMC3484623/pdf/hsrp-03-109.pdf

29. Salome CM, King GG, Berend N (2009) Physiology of obesity and effects on lung function. J Appl Physiol 108:206-211. https://doi.org/10.1152/ japplphysiol.00694.2009

30. Khanal P (2019) Patil BM. Gene set enrichment analysis of alpha-glucosidase inhibitors from Ficus benghalensis Asian Pac J Trop Biomed 9:263-270. https://doi.org/10.4103/2221-1691.260399

31. Khanal P, Patil BM, Mandar BK, Dey YN, Duyu T (2019) Network pharmacology-based assessment to elucidate the molecular mechanism of anti-diabetic action of Tinospora cordifolia. Clin Phytosci 5:35. https://doi. org/10.1186/s40816-019-0131-1

\section{Publisher's Note}

Springer Nature remains neutral with regard to jurisdictional claims in published maps and institutional affiliations.

\section{Submit your manuscript to a SpringerOpen ${ }^{\circ}$ journal and benefit from:}

- Convenient online submission

- Rigorous peer review

- Open access: articles freely available online

- High visibility within the field

- Retaining the copyright to your article

Submit your next manuscript at $\boldsymbol{\nabla}$ springeropen.com 